INTERNATIONAL JOURNAL OF

MULTIDISCIPLINARY STUDIES ON MANAGEMENT, BUSINESS, AND ECONOMY

\title{
THE PROBLEM OF COMMUNICATION OF THE SIGN AND THE SYMBOL IN THE DESIGN OF THE BRAND IN SOCIETY (ANALYTICAL STUDY)
}

\author{
Sattar Hammadi Ali AL-JUBBORI
}

${ }^{1}$ Faculty of Architecture \& Design, Middle East University, Jordan

\begin{abstract}
The sign contains two ideas, one of which is the representative and the other idea of what is represented. The problem of research has been determined in the study of these problems, which has taken place today, world, and in light of the huge number of industrial and commercial products in all their forms and origins. The sign has gained an effective role in distinguishing between these products, and it is mandatory upon these companies and institutions to protect their brand and educate the consumer about the differences between the original and the copy. In addition, because this process has become the language of manipulation of words, letters or colours. The reasons for the study are change in form or labelChange in some characters of the sign while retaining the shape of the original sign. Search results are Most imitation operations focus on the visual aspect where the imitator imitates the sign based on the same structure and construction in terms of shapes, colours and internal symbols with the original sign. The imitator changes the characters, arranges them, or adds letters to the imitation tag so as not to change the pronunciation of the original tag.
\end{abstract}

Keywords

Communication, Sign, Symbol, Design Brand.

\section{Introduction}

What does the sign mean in its general sense? What is the difference between the symbol and the sign? And what is the role of the sign and symbol in the relationship between man and reality? The symbol contains two ideas, one idea of the object represented and the other the idea of the object represented of, And the first raises the second idea in mind, then the idea is recall by mental representation, the importance of the sign is to raise the mental activity and there are types of signs, there are signs such as natural smoke, There are also artificial signs such as traffic signs and trademarks. The third type of symbol is called lingual signs and its consider cultural signs because it carries the thought and refers for a specific culture, so is there a difference between the sign and the symbol? to ask the question of the difference between the symbol and the sign takes us to another question of the relationship between the signifier and the signified and the name and the title the outside world or the relationship of names with things, there are two views of this relationship: Plato considered that the relationship between them is normal because the name in his view reflects the fact of the title or its characteristics and its natural specifications but contemporary linguists and philosophers considered it arbitrary relationship. The symbol belongs to the field of signs, but it is a symbol used in a particular sense. If the relationship between the sign and what is referred to is an arbitrary relationship, the sign that uses a symbol maintains a normal relationship between them and between what it symbolizes without a total correspondence between them. The central issue in determining the nature of the sign is to know how the sign comes to the eye and settle it as a "counterpart" of the thing you are representing. The net reference to a subject represented by an iconic document suggests that the relationship between a symbol and its meaning is based on a similarity that makes the former refer to the second without arguments. In this case, the significance of the sign comes from the same sign without using prior knowledge that can be provided by cultural teething. However, this is not the case. The visual signs, although referred to an apparent similarity, do not give us a neutral representation of an objective subject separate from human experience. The visual facts in their diversity and richness constitute a "serrated language"; human invented to communicate, connate and represent, based on this.

connotations that can be revealed within these signs are connotations that came from Cultural too thing and not an implied content Inspired by in this sense, like the units of the tongue, it is governed by facts that exist outside it, that is, they are of an natural arbitrary and it does not produce connotations only in accordance to this principle.

\footnotetext{
* Corresponding author: sattaraljboory@yahoo.com
} 
The research aims at identifying the problem of recognizing the sign and the symbol in the designs of the logos and trademarks of the consumer the role played by the sign or symbol in the symbolic representation of the consumer and the effect of the brand of desires and motivations of the consumer in the purchase process.

The search results were : The process of imitation on the famous brands and widespread in the world., Most of the imitation operations focus on the visual aspect where the imitator imitates the sign based on the same structure and construction in terms of shapes and colors and internal symbols with the original sign, as in the first, second, third, fourth and fifth., During the analysis of the samples resort to the names where the imitator to change in some characters or in order or add letters to the imitation tag so as not to change the pronunciation of the original tag, as in the first, second, fourth and sixth., The resort of the imitator in some cases to the method of mental simulation in which the imitator creates a convergence of mind between the original sign and the imitation tag by relying on contradictions and synonyms, as in the fifth case.

Research problems:

The research problem was identified in the study of the communication of the sign and the symbol which takes a scope in today's world and in light of the huge quantity of industrial and commercial products in all its forms and originals. The sign has an effective role in distinguishing between these products and it is incumbent on these companies and institutions to protect their brand and educate the consumer about the differences between the original and the imitator. Because the process has become the language of manipulation of words or letters or colors, as the researcher was able to limit the sample of traditional brands of a range of products and brands of the world-renowned and compared to the original. There are a number of questions that the research raises:

1- Can the average consumer distinguish between these signs?

2-What are the formal or color elements that the imitator can do to take the consumer recognition and raise his desires?

The most important reasons that led us to do such a study are:

1-Changesthat happens to shape or label.

2- Change in some characters of the tag while retaining the shape of the original tag sign.

Research importance:

The importance of the research comes from the importance of the brand or logo on the products that are traded by the society today and which have become part of its daily life and have consequences that are harmful to the global economy. The importance of this study is to educate and educate consumers about such a dangerous phenomenon Are common in the world and in the Arab world in particular.

Search Goal:

The research aims at identifying the problem of recognizing the sign and the symbol in the designs of the logos and trademarks of the consumer the role played by the sign or symbol in the symbolic representation of the consumer and the effect of the brand of desires and motivations of the consumer in the purchase process.

Research community:

The research community is determined by the famous global brands that have been imitated.

Research Sample:

The researcher number 6 chose global brand As they have been the most practiced in terms of tradition in most markets in the world.

Search limits:

- Spatial boundaries: global, Arab and local markets.

-Time Limits: Period from 2007 to 2018.

-Objective boundaries: Famous trademarks and logos.

Research Methodology:

The descriptive analytical approach (content analysis) was used.

Chapter Two: Theoretical Framework

1 - What is the sign?

The difference between the history of the sign and the transformation of the studies related to it. The first dimension is the old age of logic and language, while the allocation of a science is the science of the sign or the semiotic or semimology appeared with Ferdinand de Susser (1913-1857) and with Charles Alexander Pierce $(1838-1914)^{*}$.( Benkrad 2007)

The sign is the object of something else, De Susser sees the Symbol as a signifier and signified. The relationship between the signifier and the signifier is a necessary relationship such as the relationship between the two sides of the paper and the coin. (Fakhoury 1990). Pearce believes that we cannot study anything in the universe but as the systems of the (apocalyptic). We note here the convergence of de Saussure and Pierce in terms of content, as both agree that it is a sign or indication of something that is agreed upon interpretation of its meaning. The sign refers to something (or at least refers to our perception of something), and in this case, the meaning is given through the manifestation of the sign itself. There is nothing that can stand a barrier between the sign and its meanings. As for the Arabs, they have studied the sign more broadly than de Saussure has set for the sign, without assigning to the nature of the meaning. They also enter the person who is aware of them. A double 
relationship: on the one hand between the signifier and the signified, and on the other hand between these two and the conscious. (Fakhoury 1990). Pierce distinguished three types of signs:

1-Iconic Sign: A sign that shows its meaning through simulations such as pictures, objects, graphs, maps, models, and figures.

2-Indexical Sign: A sign that refers to the significance of an asymmetric relationship such as smoke to its presence on the presence of fire.

3-Symbol: A sign whose meaning is based on a convention among a group of people, such as traffic lights, a correct sign $\sqrt{ }$, an wrong sign $\mathrm{X}$, and music signs $\boldsymbol{J}$.

The signs can be categorized according to various perspectives, including voluntary signs that are intentionally and intentionally produced by humans. These are two types: the first is purely communicative; it is intended to transmit information only, such as traffic lights, fire and disaster bells, car horns. The second is aesthetic communication, In aesthetic forms, such as paintings, sculptures, and musical compositions. The involuntary signs are those that are inadvertently issued by man, and he does not control them. These are: acousticmotor-formal. (Fakhoury 1990) The signs are also characterized by natural signs, which are the signals produced by natural, which are types (sound - kinetic - formal - olfactory - sensory - sensory - sensory), from the industrial perspective are signs of industrial signs: Formal - taste - touch) It can be iconic and in the form of signals simulating what it refers to, and the two types :

1- high iconic which is in live television pictures, photographs, and some paintings, models, buildings and projects).

2-The second is low icon And the simulation is weak as some popular dances and paintings, such as Surrealism and Cubism Or are conventionally represented in signs that are not between them and what is referred to as simulations Such as traffic lights, no parking sign And a correct sign $\sqrt{ }$, an wrong sign $X$, or be simple and composite.

The question of the sign is inseparable from the concept of the symbol, since the sign and the symbol are inextricably linked to the face and the inverse. Therefore, in order for the sign to opens the need for the symbol and think about the symbol does not correct the words of the rational unless it tangled with the sign. Accordingly, the symbol boundary will be formed whenever the signs of the sign become clear.

2-What is the symbol:

The symbol is associated with all kinds of art over time and place. The arts have historically distinguished themselves with symbolic features that distinguish them from other arts. This is something in which we establish a permanent relationship between two elements (objective or relevant), and we cannot determine precisely what belongs To symbols and what cannot be classified as such, the issue is not related to the symbolic phenomenon as it appears in itself through its own characteristics, but it is the perspective adopted by this student or that. It is possible to limit the circle of the symbol in the specific functions and functions of the number and nature, that the symbol does not carry its identity in itself, this identity cannot be anything in the existence of the existence of the circulation of people and use it as such. So the boundaries of this identity can be detected only through the definition that can be known to the symbol. The symbol has no signs of its own, and does not occupy itself with a specific subject. It is everywhere. Everything is good to be transformed into a symbol from human behavior, through world themes, to language in letters and sounds, gestures and social rituals. Its existence, acts, gestures or trumpets that can be understood, understood and interpreted independently of what the symbol refers to.( Bankrad 2014)

The symbol, as defined by the British Department of Knowledge, in its 14th edition, Volume 21, is a term that refers to something visual that represents something invisible to the mind, for the relationship of their home is similar.( Ahmed 1984)

Through this definition we put our hands on one of the characteristics of the symbol, which is (duplication) as the symbol is not limited to one meaning in its significance, but extends and multiple interpretations Semantic - perhaps with multiple receptors received - within the context of art. Through this definition, we can also derive another characteristic - and, to a certain degree, of importance for the artistic symbol - the property of substitution. Although it is a term that refers to something visible, it represents something invisible, In reality, the symbol does not acquire its semantic meaning except through its presence within a certain context and its presence within a special signatory system that makes sense of it A special symbol, but in itself and in its absolute form it has no meaning $\mathrm{R}$ in the same. .( Matar 1979)

Ernst Kesserer (1874-1945) is one of the earliest philosophers to point to a new conception of the symbol by trying to determine the nature of the relationship between man and his external world. Our relationship with this world, as this philosopher sees it, is not direct, nor can it be merely an automatic link that brings together a subject. What separates man from his world is not physical barriers that are made up of things and subjects.

The philosopher (Susan Langer) distinguishes between two types of symbols: Indicative symbols, used in science, representative symbols, used in art, the first convention, the second, has no fixed meaning or rules, and cannot be replaced by other symbols as the symbols Convention. Because representation symbols are intrinsically connected, and in their opinion, the reference has no meaning to be derived from our contemplation of it but rather 
its meaning is agreed upon, whereas the representational symbols are the same in which we contemplate and act, because the link between form and content in art is a natural link, not a convention. Between the sign and the symbol says: ... "The sign" is something we act under it, or a means to serve the act, while the "symbol" a mental tool Or a manifestation of the effectiveness of the human mind. When one succeeds in communicating his idea to others by means of some symbols, we say that he has best expressed that idea. One may work long to arrive at the formulation of his opinion in the best form possible, looking for the precise words to express the meaning, and enter the words of the organization and sequence, which makes them successful tools to present his case or demonstrate his argument. There is no doubt that such a mental effort cannot be included in the spontaneous response: it is clear that the difference between the expression of the idea and the expression of the emotional state. However,( Ibrahim 1988) Hegel finds that there is a fundamental difference between the symbol and the sign the symbol is arbitrary, while the symbol includes the representation that it expresses. A lion, for example, uses a symbol of power, a fox is a symbol of deceit, (and so on, so it seems that the symbol is not entirely arbitrary. But it should not be understood that the symbol corresponds to the full conformity, because it carries peculiarities that do not exist in the signifier.( Hegel 1986) Anthropologists also divide the symbols into two main categories:

Individual symbols and group symbol Edmund Leach went on to say that there are two types of symbols: the first type Public Sociological Symbols The second type is the Private Psychological Symbol.

This distinction is simply a description of the different (reference frames) under which the anthropologist or the psychologist studies human behavior. Edmund Leach goes on to explains the two types saying The general symbols are those symbols which require reaching a collective agreement of the basic meaning of these symbols. Thus, these general symbols become a means of communication between the giver and the receiver. Leach gives an example traffic police officer When he raises his hand, everyone here agrees that this means only one meaning that cannot tolerate any other meaning. and in special symbols, For example, if we are dealing with a man who is kissing a beautiful girl This may have more than one explanation that may be the relationship between them is purely a friendship and may it's an emotional relationship or sexual. Hence, this behavior carries an individual or special symbol Therefore, (Abu Zeid 1985) the symbol is a way to express emotions and feelings as abstract things on a hand, and on the other hand, a way to formulate a "intellectual" experience through which something is intended to symbolize the image by hinting or suggesting some things or feelings and emotions shared between him and what indicates on him.

\section{3- The Sign and icon in graphic design:}

The icon is one of the most common tools used by a graphic designer to create a logo. When designing a logo for a company, one of the key things is identification, in other words a clear representation of what the company is, and for us in the design world, usually a set of schematic elements representing something, in other words, is the picture that tells the story, and our concern as designers lies in how Use symbols correctly, to avoid any misrepresentation. Plato introduced it into his own philosophy. The philosopher believed that the codification of language was the domain of the legislator, who knew how to make words, because names must be of the kind of things they express., So as to be identical to them and can influence them. Plato's thesis, in this way combines two scenarios: the philosophical perception that the language is a simulation of nature, and the classical philosophical perception that makes language limited to some legislators and wise people. Linguistic Images Z shapes and colors reflect the sex of this stuff. For example, the logo of IBM, which contains a hidden message to the whole world hidden in the company's big blue logo, where there are white lines passing through the logo, the hidden corporate destination of this logo is a sign of equality, look at the lower right corner. See Figure (1)

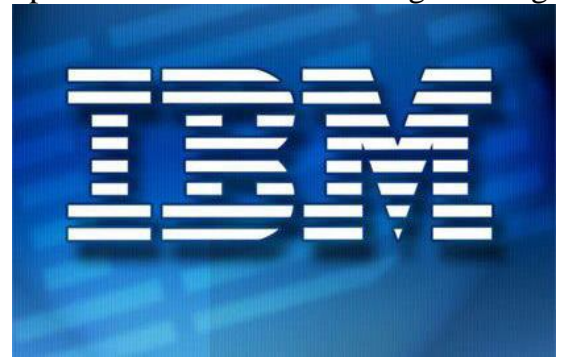

Figure No (1) IBM logo - (http://www.arabapps.org)

Some believe that Logo is actually a symbol, but it is not just as some people think, but the logo becomes a symbol of the company's identity based on the visual expression of these logos and symbols that give the company its identity and integrate with the citizen's life. Its design depends on three important aspects: And technical sense.

The designer should consider three basic criteria when designing the logo:

1 - That the designer does not rely on another logo quotes from the most prominent content.

2. The logo expresses the purpose for which it was designed.

3. Simplicity in shape. 
4 - lack of colors, suitability and harmony.

Chapter Three: Sampling Analysis and Results

Case Studies: First case: Adidas sign

At first glance, the beholder sees that this product is a sports bag for Adidas based on the form accompanying the existing written letters. It focused on the visual aspect by imitating the shape in terms of construction and making it four slanted and long lines instead of three and the same spirit. This situation cannot be understood before. The simple consumer, either the writing has been able to manipulate the letters and what does not affect the pronunciation of this tag resorted to change the letter $d$ with the letter $b$ are very similar in form of the last letter $\mathrm{d}$ was the skill of the imitator to choose the letter a very close to the letter $\mathrm{d}$ and this letter from the letter ITC Avant Garde Bold and Fig The following typography illustrates this manipulation.

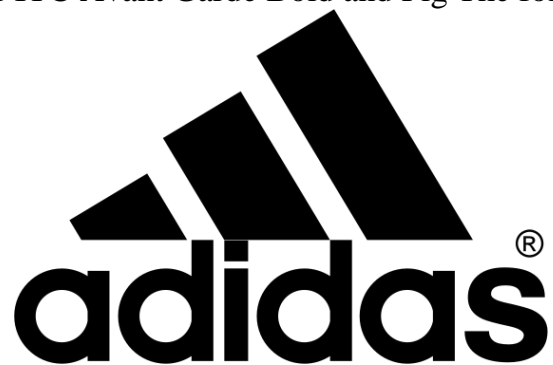

Figure No(2) Original tag image

-(https://www.buzzfeed.com/jessicalima/falsificaciones-de-marcas-que-te-daran-risa-y-lastima-al

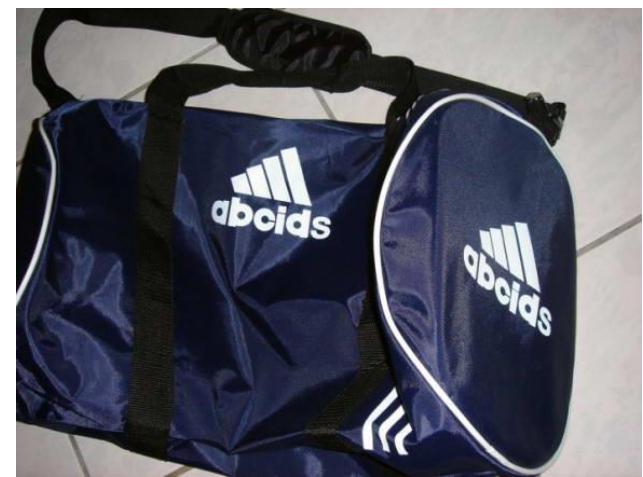

Figure No (2-1) Replica tag-

(https://www.buzzfeed.com/jessicalima/falsificaciones-de-marcas-que-te-daran-risa-y-lastima-al

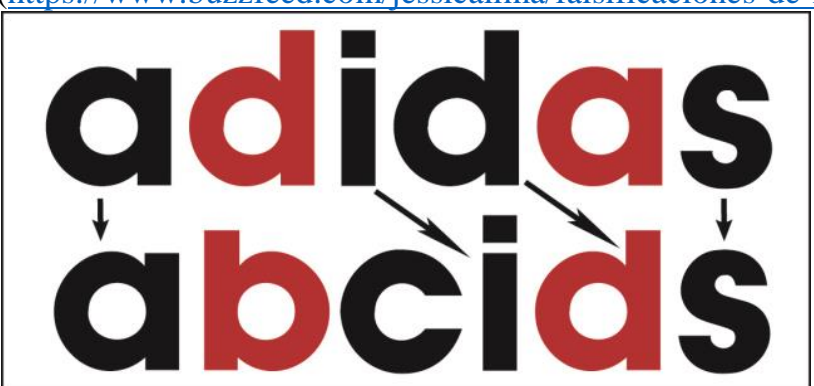

Figure No (2-2) Structural analysis of the shape of the original letters used in replication Work of the researcher

The second case: Puma sign

Try the imitator and do not tell the designer to focus on the visual and typographic sides, we find him employed the same shape of the animal jumping almost identical except for the area of the head of the animal, which replaced his ears with hair to the top and this observation is very accurate cannot be observed, puma and in the same spirit, but as we observe in Figure 3-2 a manipulation of the third and fourth letters, where the letter $\mathrm{m}$ was replaced with the letter "A" and "A", which was very close to the spirit of the original letter. 


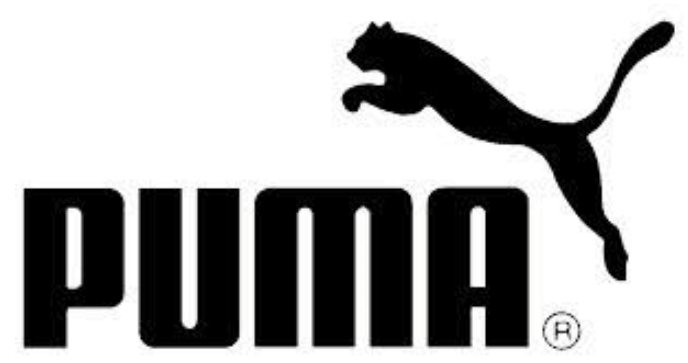

Figure No (3) Original tag image https://www.buzzfeed.com/jessicalima/falsificaciones-de-marcas-que-te-daran-risa-ylastima-al

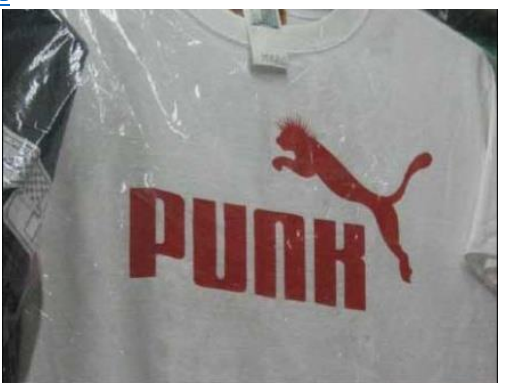

Figure No (3-1) Replica tag

https://www.buzzfeed.com/jessicalima/falsificaciones-de-marcas-que-te-daran-risa-y-lastima-al

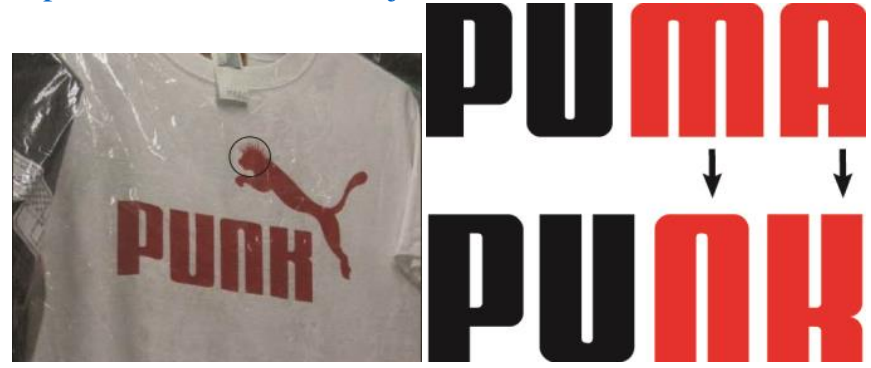

Figure No (3-2) Structural analysis of the shape of the original letters used in imitation. Work of the researcher

Third case: McDonald's sign

The McDonald's chain of restaurants is famous in different countries of the world and just to see the letter $\mathrm{M}$ with its movement and its usual controls, in conjunction with the yellow and red color, these restaurants and meals come to mind. The imitator was able to play on the visual perception of the consumer where the imitator imitates the sign based on the same structure and construction on the one hand Shapes and colors and internal symbols with the original sign with a simple manipulation in the position of the character $\mathrm{M}$ and focus on the color component, and also used mental simulations in which the imitator creates a mental affinity between the original tag and the imitation tag by relying on contradictions Synonyms.

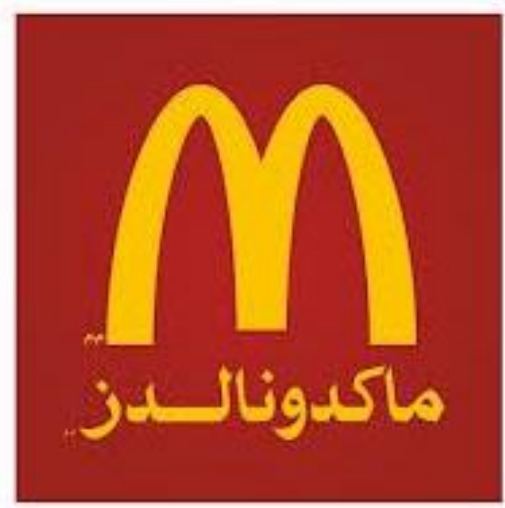

Figure No (4) The original tag

https://www.buzzfeed.com/jessicalima/falsificaciones-de-marcas-que-te-daran-risa-y-lastima-al 


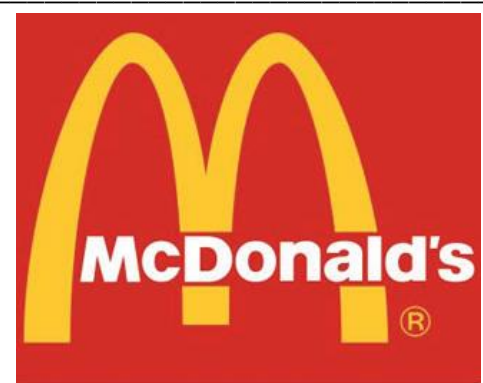

Figure No (4-1) The original tag

https://www.buzzfeed.com/jessicalima/falsificaciones-de-marcas-que-te-daran-risa-y-lastima-al
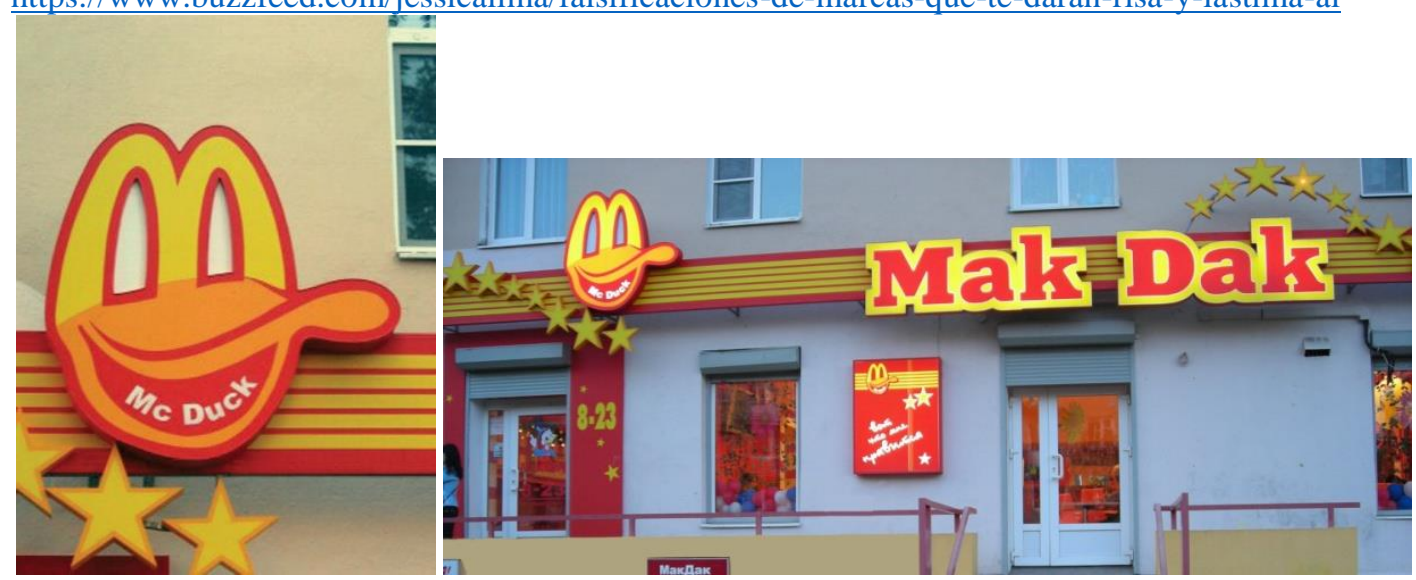

Figure No (4-2) Replica tag

https://www.buzzfeed.com/jessicalima/falsificaciones-de-marcas-que-te-daran-risa-y-lastima-al

\section{Fourth Case: Sign in SONY}

Sony's logo was designed with a transparent type of typography and without any formal additions. The company adopted a new character called SONY FONT which made it easier to imitate this slogan. The imitator adopted a simple game by modifying the letter $\mathrm{O}$ and making it $\mathrm{Q}$. This is one of the methods used by imitators to change The letters of the names do not affect the general shape and the artistic construction of the logo (note Figure 5-2).

\section{SONY}

Figure No (5) The original image tag

http://micetimes.asia/look-like-chinese-counterfeits-of-famous-brands/ 


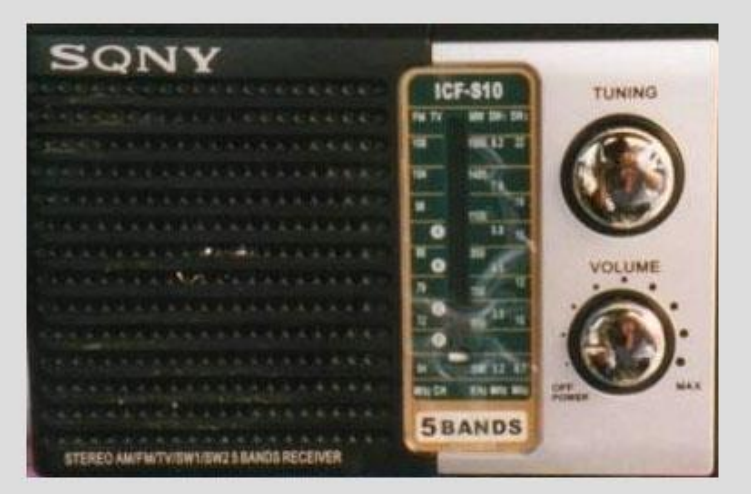

Figure No (5-1) The imitation tag

http://micetimes.asia/look-like-chinese-counterfeits-of-famous-brands/

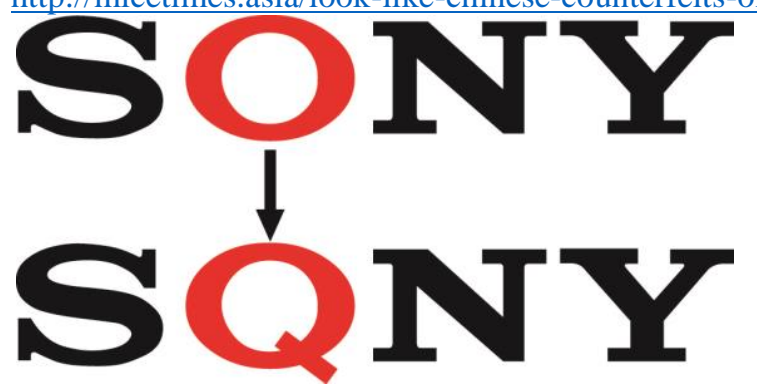

Figure (5-2) Structural analysis of the shape of the original letters used in imitation. Work of the researcher

Fifth Case: The Cheese Label Lavache quirit

This is the way in which the imitator has resorted by focusing on the shape of the head of the laughing cow, which has become a distinguishing sign for the mere consideration of it. The consumer comes to mind and his knowledge store is the loaf of Kerry's loaf And this method is popular in most of the replicas, as some resort to mimickers to convert the image of the image to the form of a decree relying on the psychological and physiological side of the consumer as the process of awareness and motivation is done during the first moment of viewing without the For details entry.

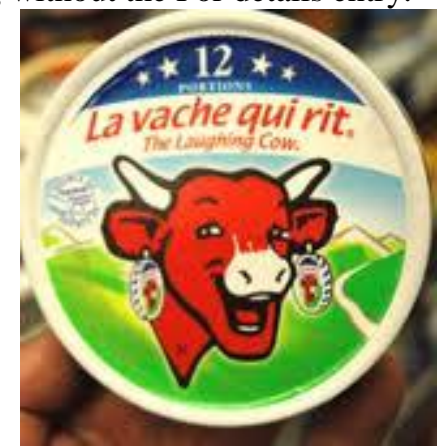

Figure No (6) The original image tag

https://www.pinterest.com/saundersaul/la-vache-serieuse

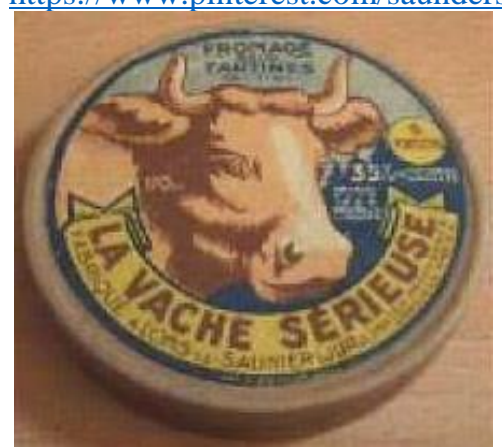

Figure No (6-1) The imitation tag https://www.pinterest.com/saundersaul/la-vache-serieuse 
Sixth Case: Starbucks Coffee Logo

The focus of the imitator here on the visual aspect where the tradition of the sign based on the same structure and construction in terms of shapes and colors and internal symbols with the original sign, we note that the overall shape of the logo is the circle and the method of distribution of writing inside and even color, giving the initial impression of the viewers as the famous Starbucks But despite the fact that it is pronounced in the same way as the original (STAR) pronunciation, the most noticeable thing here is the emphasis on the green element and its contrast with the letter forms. (Note figure 7-2).

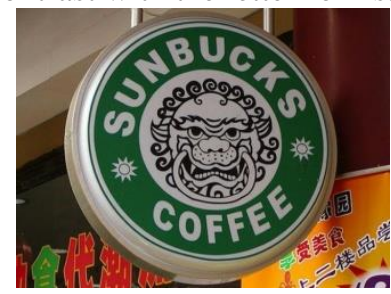

Figure No (7) Original tag

taghttps://www.buzzfeed.com/jessicalima/falsificaciones-de-marcas-que-te-daran-risa-y-lastima-al

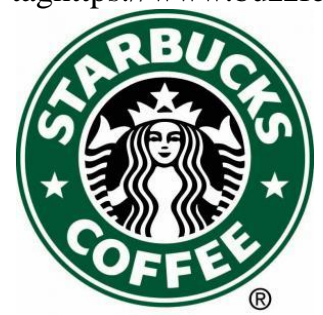

Figure No (7-1) Replica

taghttps://www.buzzfeed.com/jessicalima/falsificaciones-de-marcas-que-te-daran-risa-y-lastima-al

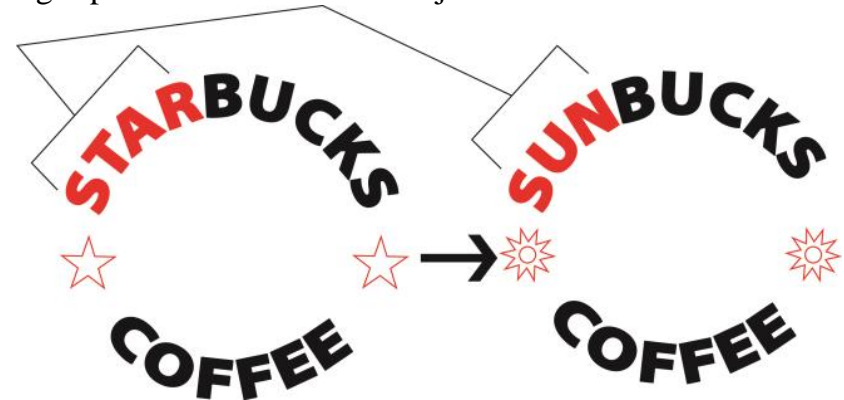

Figure No (7-2) Structural analysis of the shape of the letters and shapes used in the tradition. Work of the researcher

Research results:

In light of the above, it is possible to limit the most important results that emerged from the researcher are:

1 - The process of imitation on the famous brands and widespread in the world.

2 - Most of the imitation operations focus on the visual aspect where the imitator imitates the sign based on the same structure and construction in terms of shapes and colors and internal symbols with the original sign, as in the first, second, third, fourth and fifth.

3 - During the analysis of the samples resort to the names where the imitator to change in some characters or in order or add letters to the imitation tag so as not to change the pronunciation of the original tag, as in the first, second, fourth and sixth.

4 - The resort of the imitator in some cases to the method of mental simulation in which the imitator creates a convergence of mind between the original sign and the imitation tag by relying on contradictions and synonyms, as in the fifth case.

The researcher recommends:

the need to reduce this phenomenon by spreading the awareness of graphic and advertising among consumers and activating laws that limit the phenomenon of imitation because of its great economic effects on the national economy.

\section{References}

Abu Zeid, Ahmed. (1985). Code and myth and social construction, the magazine of the world of thought, Volume XVI number three. Classical $\mathrm{P}$

Ahmed , Mohammed Fattouh. (1984). Symbol and Symbolism in Contemporary Poetry, Cairo, Dar Al Ma'arif. 
Al-Khamash, D. Sulaiman. 1428H. lexicon and semantics, the site of the Arab tongue : http://www.angelfire.com/tx4/lisan, Saudi Arabia.

Bankrad,Said. (2014). Electronic Signs Magazine, retrieved on 26/1/2014 from :http://saidbengrad.free.fr/en/art21.htm.

Fakhoury, Adel. (1990). Currents in Al-Sihemia, Beirut, Dar al-Tali'ah.

Hegel. (1986). Romantic Classical Symbolic Art, translated by George Tarabishi, Beirut, Dar Al Taliaa for Printing and Publishing.

Matar, Amera Helmi. (1979). Introduction to aesthetics, Beirut, Dar al-Nahda Arab.

Zakaria, Ibrahim. (1988). Philosophy of Art in Contemporary Thought, Cairo, Egypt Library.

Received: February 15, 2019

Accepted: April 20, 2019 